\title{
Evaluating the effectiveness of a large-scale professional development programme
}

\author{
Katherine Main* and Donna Pendergast (iD \\ Griffith University
}

(Received 6 December 2015; accepted 23 September 2016)

An evaluation of the effectiveness of a large-scale professional development (PD) programme delivered to 258 schools in Queensland, Australia is presented. Formal evaluations were conducted at two stages during the programme using a tool developed from Desimone's five core features of effective PD. Descriptive statistics of 38 questions and thematic content analysis of open-ended responses reveal that the PD programme was reported to be effective for all five domains evaluated: duration; content focus; active learning; collective participation; and coherence. Recommendations arising from the planning and delivery of the programme include that future PD should be designed and evaluated in line with the framework that considers the eyidence-based features of effective PD.

\section{Introduction}

Implementing systemic change in schools is challenging, especially when it involves reform that requires upskilling of school leaders and classroom teachers. In 2015, all Queensland schools were required to engage in a significant reform with Year 7 students moving from primary into high school settings (Queensland Government 2015). In addition, all government schools were required to implement a particular approach to the delivery of the middle Years 7-9, known as Junior Secondary, which involved the activation of six Guiding Principles (Australian Council for Educational Research 2012) with concomitant adjustments to structural, philosophical and pedagogical practices. In preparation for this major reform, the Department of Education, Training, and Employment commissioned a large-scale professional development (PD) programme called the Junior Secondary Leading Change Development Program (hereafter the Program). This Program was delivered in 2014 to the school principal and two school leaders of all 258 state schools across the state. The PD Program was designed to build capacity for school leaders to facilitate effective change in their school site. The research reported in this article shares the findings of data collected at two points along the Program implementation which enable insight into the effectiveness of the professional learning.

\section{The large-scale reform setting}

Educational change is complex and ubiquitous and is driven by a range of reform agendas (Fullan 2001). Literature in the field confirms that schools often implement

*Corresponding author. Email: k.main@griffith.edu.au 
a number of reforms simultaneously in an effort to meet the imperative to improve student learning outcomes (Organisation for Economic Cooperation and Development 2015). The challenge for school leaders is how to adapt reforms for local contexts and to implement them successfully and ensure their staff are not hampered by reform fatigue (Hallinger and Heck 2010). This is all the more challenging because systems and schools are multifaceted, with starting points that are different, as well as system leaders having to face multiple choices and combinations of decisions 10 along the reform path (Mourshed et al. 2010). The reform of the middle years was undertaken in a context which had all of these features, and PD of school leaders and their staff was key to its potential success.

There are eight predictable elements that contribute to reform improvements, ranging from understanding where the system is situated with regard to a range of

15 features, to specific leadership, classroom and structural factors (Mourshed et al. 2010). A 'spark' is often required to trigger major change and a system can make significant gains from wherever it starts and a timeline of six years or less is achievable' (2010, p. 14). This spark can be the result of a crisis or a major reform initiative and is recognised as necessary to create the urgency for change (Kotter 1996,

20 Kotter and Cohen 2002). For reform to be sustained oyer the long term, improvements must be integrated into the 'very fabric of the system pedagogy' (Mourshed et al. 2010, p. 71). That means that teachers and school leaders must be at the core of the implementation, and hence there is a need for PD.

In order for reform to be sustainable, the shaping of leadership is an imperative (Hargreaves and Fink 2012) and in the case under investigation leaders and teachers were identified as both the subjects and agents of change (Australian Council for Educational Research 2012, Author/s 2013). Leaders needed to be provided with opportunities for professional learning and to enable others to take risks, particularly related to their pedagogical practices. Given that the context is set in the middle 30 years, the National Middle School Association further noted that leaders must be 'committed to and knowledgeable about this age group, education research and best practice' and be 'courageous and collaborative' (2001, p. 28). This means being willing to break down strongly held historical traditions pertaining to education for adolescents (Vagle 2012). The sustainability of such reforms requires leaders who 35 support teachers within their school by facilitating explicit PD in the necessary pedagogies associated with the reform and ensuring that continuity for those practices is then implicit within the school context (Schleicher 2012).

\section{The need for professional development}

The need for PD was foregrounded in the values that underpin the impending reform. It has long been accepted that a unique approach, based on the developmental characteristics of young adolescents and their particular needs, is required when teaching in the middle years (McGee et al. 2003) and this was highlighted as an educational priority by the Ministerial Council on Education, Employment, Training and Youth Affairs (2008) which consisted of the Education Ministers in each of the 45 Australian jurisdictions, along with representatives of the Catholic and independent school sectors. The Middle Years of Schooling Association (2008) MYSA Position Paper identified professional learning as a core strategy to achieve this objective. Further, the paper noted that there was a need to 'provide ongoing professional learning to enhance teacher knowledge and understandings of the middle years and 
how this impacts on learning' and 'a need to resource systemic processes for ongoing professional learning' $(2008$, p. 2).

Factors that enable systems to improve include not only enhancing teacher quality but also the building of teacher efficacy as one of six 'must haves' for effective reform (Mourshed et al. 2010). Luke et al. (2003, p. 137) concur, noting that there must be 'a strong multi-partner professional development focus on middle years curriculum and pedagogy' for effective and sustained change'. Historically, there has been a poor alignment with reform initiatives and effective $\overrightarrow{P D}$, with a focus on the mechanical implementation of the reform but with little attention to the needs for supporting leadership and learning (Riley 2000, Organisation for Economic Cooperation and Development 2015). Such 'compliance' models of reform fail to build the social and human capital in schools necessary for sustained change (Hargreaves 2002). Further, with regard to PD that is focused on the middle years learner and middle schooling practices, PD opportunities have been found to be 'oversubscribed ... somewhat piecemeal, and often unconnected' (Luke et al. 2003, p. 133). Indeed, PD programmes are most often offered as isolated opportunities in response to immediate individual, school or district needs without a considered approach or overarching strategy for whole system improvement (Author/s 2015). Where a whole-of-system change is to take place, a whole-of-system approach to professional learning must be implemented concurrently. This provides an excellent context for investigating the effectiveness of targeted large-scale PD.

In Queensland, Australia, where this Program was implemented, the approach that school leaders and teachers needed to harness to effectively reform the system was guided by The Junior Secondary Guiding Principles outlined in A Flying Start for Queensland Children (Department of Education and Training 2010). This is one of the most significant reforms undertaken in Queensland education and has been supported by a systemic policy commitment, including resource allocation and the Program under investigation in this article, ensuring it is supported both at the individual school level and in the wider schooling system, thus providing optimal conditions for effective reform (Stevens 2004).

There is a growing body of literature supporting the claim that evidence-based PD programmes work (Mouza 2009, Australian Institute of Teaching and School Leadership 2012, Hill et al. 2013). That is, where PD programmes are explicitly and purposefully developed to align with the core features of effective PD, positive outcomes in teachers' changed and enhanced practices have been demonstrated. Central to the aim of this Program was to provide continuing and targeted professional learning for school leaders to ensure their readiness to accept Year 7 students into their Junior Secondary structure and, where schools already had either a P-12 structure or a $\mathrm{P}-10$ structure, it also aimed to enhance and improve pre-existing Junior Secondary models with sound philosophical and educational practices. As such, the Program was purposefully aligned with the five core features of effective PD models outlined by Desimone (2009).

\section{Measuring the effectiveness of professional development}

There are a large number of features reportedly impacting on the effectiveness of PD. After an extensive critical review of the PD literature, Desimone (2009) developed a core conceptual framework which was used as the basis for an instrument (Author/s 2015) designed to reflect on the effectiveness of PD. The features of this 
conceptual framework incorporate the core features for effective PD together with the "variables that mediate (explain) and moderate (interact to influence) professional development's effects', such as school leadership and context, and the teachers themselves (Desimone 2009, p. 184). As noted by Desimone, the five core features that are widely endorsed by the field as being critical components for effective teacher PD are as follows:

(a) Content focus: refers to the knowledge and skills necessary for teachers to carry out their day-to-day work with respect to the topic of the professional learning, within the classroom.

(b) Active learning: refers to opportunities to be actively engaged in meaningful discussion, planning and practice during the PD activity and the reality of their day-to-day work.

(c) Coherence: refers to the connection between the PD activity and the reality of the classroom

(d) Duration: refers to the need for the PD to be of sufficient duration to enable engagement, leading to possible intellectual and pedagogical change. O'Brien (2006, p. 7) noted that 'the most effective professional learning programs consisted of multiple days, preferably based in schools, over a period of time';

(e) Collective participation: refers to the opportunity for participants to undertake PD with others from the same school or group that sets up potential for interaction and discourse, which can be a powerful form of learning.

However, despite general consensus around what constitutes effective PD, there is a lack of evidence based on these principles (Mouza 2009, Hill et al. 2013). Hence, this study goes some way to re-addressing this shortfall by investigating the effectiveness of PD around a major reform with a large number of participants.

As well as core features for the content of $\mathrm{PD}$, there are also critical levels of information necessary to be able to evaluate $\mathrm{P} \widehat{\mathrm{D}}$ and gather evidence of its usefulness in changing practice. Guskey (2002) posited a framework that showed there are five critical levels of information or data-gathering points necessary to provide evidence around the effectiveness of the PD: participants' reactions (satisfaction with the PD experience); participants' learning (new knowledge and skills gained); organisation support and change (organisation advocacy and support for change if necessary); participants' use of new knowledge and skills (level of implementation); and student learning outcomes (cognitive, affective and/or psychomotor). The first two of these critical levels of information can be evaluated by the PD facilitators in this study at the time of delivery. That is, through surveys or other data-gathering instruments, the PD facilitators can seek immediate feedback around how satisfied participants were with the PD and whether they perceived they had gained new knowledge or skills through the PD. The focus of this PD evaluation is to ascertain the effectiveness of the PD at the point of delivery; that is, Guskey's first two levels of data gathering. It should be noted that the information necessary for the final 45 three levels require the collection of longitudinal data in situ, and with this a systemic commitment to resources over considerable time. Reflecting on the Educational Change Model developed by Author/s et al. (2005) which has also been adopted as the underpinning reform model for the implementation of Early Childhood reform in another state in Australia (Garvis et al. 2013), a reasonable timeline 
for achieving the final three levels ${ }_{\Lambda}$ is five to eight years. This is consistent with the timeline proposed by Mourshed et al. (2010).

The focus of this article is to demonstrate the alignment of the Program's design with the core PD features identified by Desimone (2009) (i.e. content focus, active learning, coherence, duration and collective participation) and to provide an evaluation of the effectiveness of the programme in line with Guskey's (2002) first two levels of information; that is, did participants perceive that the PD was of value; and were they able to 'take away' new skills and knowledge that related directly to their day-to-day core business as a teacher? It should be noted that the third level, organisation support and change, is evidenced by the whole-of-system support provided by the Department of Education and the engagement in the process by school leadership teams and staff. The final two levels of evaluation require further data to be collected over time.

\section{The Program design}

The PD Program was designed to build school leader capacity to direct effective change processes in schools. The role of leadership teams in guiding school communities through this reform required a planned and deliberate approach to enabling change that reflected the needs of each individual context, and thus there was no 'one-size-fits-all' approach. During 2014, three members of the leadership teams in all 258 public secondary schools across Queensland participated in the Program (Author/s et al. 2014), which was multifaceted and conceptually built around a distinct model known as the Educational Change Model (Author/s et al. 2005) and aligned with the core features of effective PD (Desimone 2009). The Program was designed for schools commencing this journey as well as for other purpose-designed schools, including those that had been pilot schools beginning their journey of reform in 2012. In this way, the Program aimed to work with all schools to further progress the development of their Junior Secondary programme. The Program involved three stages, as presented in Table 1.

One of the design features of the Program was the commitment to conduct research into a number of facets including the effectiveness of the PD. Hence, the Program design incorporated data collection related to PD effectiveness at two key junctures: the end of the two-day PD conference at each of the seven locations; and the end of the one-day workshop which coincided with the end of the Program.

Table 2 presents the alignment between these five core features and the stages and activities of the Program.

For the purposes of this study, Desimone's (2009) effective PD conceptual framework was utilised to inform the development of the Program as a whole and a survey instrument, the Targeted Professional Development Scale (TPDS), was used to determine the effectiveness of the PD experience in which school leadership teams engaged. The development and refinement of this instrument has been reported elsewhere (Author/s 2015). Desimone's (2009) framework also highlights the goals of PD in terms of increasing teachers' knowledge, skills and attitudes together with the resulting changes to practice and benefits for students. The evaluation survey data were collected at various stages in the Program. The first data collection point was at the end of the two-day learning conference (Instrument 1); the second at the end of the 1-day workshop (Instrument 2). 
AQ32 Table 1. Junior Secondary Leading Change Development Program project stages.

Stage

Activity

Timeline (2014)

1

Two-day professional learning conference for school leaders

Delivered in each of the seven regions in the state, the focus of the two-day conference was for three school leaders from each school to determine their school's current phase of reform by being guided through a range of sessions that utilised a comprehensive suite of resources available to all schools via provision of a loaded USB device for each school as well as access to a purpose-built interactive website. Resources provided theoretical information and evidence-based research related to adolescent learners, the six Guiding Principles, the Educational Change Model and quality teaching strategies. Information, PowerPoint presentations and activities were developed for 28 topics ranging from effective practices for adolescent learners to building teams within schools

2 Implementation with coaching support, including development and/or further refinement of an Action Plan and webinars

All 259 schools were placed into one of 22 clusters that were negotiated with advice from regional representatives. Each cluster included approximately 10 schools and was allocated two professional coaches. For three to four months the coaches were available for direct support to assist schools with their Junior Secondary 'Action Plans' as well as providing feedback and advice on three structured milestones

In addition to the coaching process, four webinars were presented on topics that were most frequently requested by school leaders during the two-day conferences and the coaching dialogues

3 One-day workshop for school leaders

May-September

These were co-delivered in the seven regions and constituted the final phase of the Program. It provided an opportunity for the school leadership teams to reflect on and share their Action Plan achievements and their readiness for the change in 2015. These workshops were structured around the concept of educational Best Practice, with a focus on three key themes: Transition; Quality Teaching; and Evidence-based Practice. Schools were given opportunities to network and to share their successes in their programme implementation efforts, with schools invited to present a snapshot of Best Practice in one of the three targeted areas.

\section{Instrument 1}

This survey incorporated the TPDS based on the five core features identified by Desimone (2009). This tool was shown to be a valid and $\hat{\text { reliable instrument to mea- }}$ sure the effectiveness of PD (see Author/s 2015). The administration of this tool enabled the evaluation of the Program in line with the first two of Guskey's (2009) recommendations for data collection; that is, participants' satisfaction with the PD experience and participants' gaining of new knowledge and skills. The TPDS has two parts: demographic information; and an evaluation of the PD programme under the five core features of effective PD $($ content focus; active learning; coherence; 
Table 2. Alignment of the five core features of effective professional development and the stages and activities of the Junior Secondary Leading Change Development Program.

Core features of effective PD

Stages and activities of the Program

Duration

Stages 1, 2 and 3

Collective participation Stages 1, 2 and 3

Coherence

Stages 1, 2 and 3

Content focus Stages 1, 2 and 3

Active Learning Stages 1,2 and 3
The Program ran from April 2014 to October 2014 with many opportunities for participants to learn, implement and receive feedback

The Program was designed to be delivered to school leadership teams. All activities were completed within and across school teams. Participants engaged in a range of individual (school teams of three); small group (multiple school teams); larger group (school clusters between seven and 15 schools); and whole group (whole of region) activities to encourage collaboration and cooperative learning The Program was specifically targeted to build the capacity of school leadership teams around Junior Secondary. Self-assessment activities and shared experiences underpinned the PD. All activities undertaken by participants throughout the PD were directly related to their school's context

The Program included sessions with semi-structured activities that utilised a bank of resources focused on Junior Secondary principles and practices as well as the adolescent learner. A copy of these resources was provided each school to enable leadership teams to identify and self-select the focus of the PD they would engage in. Every stage of the programme was tightly focused around Junior Secondary and Junior Secondary practices

Throughout the two-day conference, the coaching programme and the one-day workshop, school leadership teams (SLT) were presented with a number of tasks that they needed to complete collaboratively. They also had the opportunity to complete other activities which furthered their school's goals. The programme was designed around the SLT leadership teams developing and/or refining their school's action plans during Stage 1; implementing and reporting on their progress during Stage 2; and reflecting and sharing experiences in Stage 3

duration; and collective participation). A total of 38 specific items framed as statements were developed for each of the five core features. For each item a Likert scale with five points - ranging from 'Strongly Disagree', to 'Disagree', 'Neither Agree nor Disagree', 'Agree' to 'Strongly Agree' - with opportunities for open-ended responses was provide $\widehat{d}$. There was space at the end of each of the five sections enabling open-ended responses to be added by respondents. This ensured that quantitative data in the form of ratings from the Likert scale, and qualitative data in the form of open-ended comments, could be analysed to add greater depth to the feedback provided.

Table 3 presents a sample of the survey for the core feature Content Focus and the related questions, showing a mixture of valence statements. The instrument had a similar format for each of the five core areas.

The survey was administered to all participants at the conclusion of the two-day conference. The survey was also available for completion online. However, few respondents utilised this method. Both online and paper responses were collated into one data-set. Surveys were completed anonymously. 
Table 3. Core features and related questions in the instrument for the area of Content Focus.

Core features of effective PD

Items as specific questions listed for comment on a five-point Likert scale

Content Focus

Knowledge and skills refers to the knowledge and skills necessary for you to carry out your day-to-day work within your classroom
1. I gained new knowledge or skills that are related to my profession

2. I would not be able to integrate this PD into my day-to-day practice

3. The PD will enhance my teaching strategies

4. I can/see areas related to today's topic where I can improve or learn more

5. The PD topic is important because it links directly to state or national goals

6. The PD will not help me meet the needs of more students

7. The PD activity takes into account the learning needs of all the teachers in attendance

8. This PD did not meet my learning goals

9. I believe my knowledge and skills are enhanced through this PD

The demographic data collected were the respondent's leadership position (principal, deputy principal, head of Junior Secondary, other) and region (from a possible seven regions)). These categories were originally incorporated as a useful means of further exploring the data, allowing comparisons to be made between regions and leadership positions. The lack of identifying information enabled respondents to provide anonymous ratings and comments, thereby enhancing the validity of the responses. A total of 465 (total participants $N=685$, response rate $=68 \%$ ) responded to Instrument 1 for the two-day conference.

\section{Instrument 2}

10 This survey was administered at the end of the one-day workshop. At this stage in the Program, participants had completed all aspects of the PD planned, including coaching, webinar participation and both learning experiences. This survey incorporated the TPDS and demographic information as in Instrument 1, but this time applied to the one-day workshop; in addition, questions related to

15 participants' overall perceptions of the effectiveness of the Program in terms of increasing understanding, content and process effectiveness. A total 278 (total participants $N=421$, response rate $=66 \%$ ) responded to Instrument 2 for the one-day workshop. For the purposes of this article, the focus will be on reporting the data related to the TPDS. 


\section{Data analysis}

A mixed-methods approach to data analysis was employed whereby SPSS (version 22) was applied to analyse the quantitative data at the level of descriptive statistics and Leximancer was used to analyse the qualitative data in the extended responses on the survey. Leximancer is an analytics software tool designed to examine the word co-occurrence in unstructured, qualitative textual data in a way that provides an unbiased, objective and automatic discovery of themes, concepts and their associated relationships. Data that are 'mined' through Leximancer produce maps with emerging themes and concepts and associated relationships that can be analysed and interpreted (Smith 2006).

For the purposes of the evaluation of the Program, Duration referred to the need for PD to be of sufficient duration to enable engagement leading to possible intellectual and pedagogical change. Content Focus was about the knowledge and skills necessary for participants to carry out their day-to-day work within their schools. Active Learning related to opportunities to be actively engaging in meaningful discussion, planning and practice during the PD activity and the reality of the dayto-day work within their school context. The next concept the participants were asked to report on was Collective Participation, which related to the opportunity for them to undertake the $\mathrm{PD}_{\alpha}$ with others from the same school/department/group that sets up the potential for interaction and discourse, which can be a powerful form of learning. Finally, Coherence referred to the connection between the PD activity and the reality of participants' day-to-day work experiences within their schools.

Prior to analysis, the following items were reversed: Duration, items 2, 3, 4 and 6; Content Focus, items 2, 6 and 8; Active Learning, items 4 and 7; Collective Par-

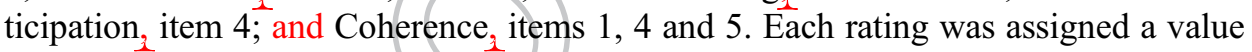
from zero to four: 'Strongly Disagree' $=0$; 'Disagree' $=1$; Neutral' $=2$;

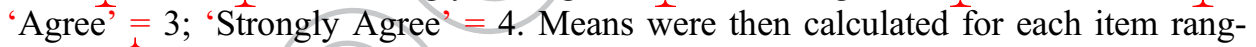
ing from possible minimum and maximum values of zero and four, respectively.

\section{Findings and discussion}

Responses from the TPDS (Author/s 2015) were used to gather evidence regarding each/eadership team member's perceptions of the effectiveness of the Program as a form of professional learning (Guskey's critical levels of Information 1 and Information 2). The administration of Instrument 1 at the end of Stage 1 and Instrument 2 at the end of Stage 3 enabled longitudinal understandings of the effectiveness of the conference programme itself as a form of professional learning throughout 2014. The findings are now reported as a collective for each of the five core areas. After analysing the data it was decided that reporting according to leadership role or geographic region added little value to the discussion because there were no significant differences based on these demographic features. However, in the quotes provided to illustrate key themes, the leadership position of the respondent is used for reporting because this occasionally adds context to the response provided and the region number is noted to demonstrate that the comments have been drawn across the seven regions. 


\section{Duration}

Table 4 presents the means aggregated for the seven regions for each of the six statements assessing Duration, taken from data provided in Instrument 1 and Instrument 2. Also shown are the overall means for each statement. For the two-day conference, participants agreed most (overall mean was 3.10) with the statement 'I believe the PD sessions were long enough for me to engage with the ideas' and agreed least (overall mean was 1.93) with the statement 'I think there would be a benefit from spreading the PD over more days/sessions'. These two pieces of data taken together indicate that overall the participants felt the duration of the conference was sufficient for them to fully engage with the material. Again, for the one-day workshop, participants agreed most (overall mean was 2.98) with the statement 'I believe the PD sessions were long enough for me to engage with the ideas. Participants agreed least

15 (overall mean was 1.70) with the statement 'I would like this PD to include followup sessions over time' and (overall mean was 1.81) with the statement 'I think a refresher course is needed to remind me of the details of the PD'. Overall, the results about Duration indicate the participants felt that the duration of the conference was sufficient.

20 The Leximancer thematic analysis of participants' comments identified two major themes regarding Duration. These were the provision of 'time to plan' and a minor theme of the conference being too late'. The participants commented positively on the opportunity to have the time to spend with their colleagues; something they often do not get the chance to do given the busyness of their everyday lives in 25 schools. They particularly enjoyed that they were able spend time working as a leadership team from their own school but also with their own clusters and regions. These findings concur with Desimone's (2009) recommendations that the duration of the PD needs to be sufficient to provide participants with opportunities to engage with the materials to effect potential change. The multiple-day approach was also 30 reported to be sufficient in terms of duration (O'Brien 2006). The following comments exemplify these trends:

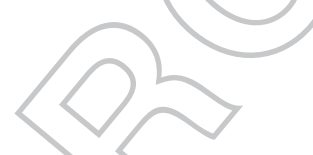

Table 4. Overall mean ratings for the two-day conference and one-day workshop for each of the six items assessing Duration.

\begin{tabular}{lcc}
\hline & \multicolumn{2}{c}{ Mean $^{\mathrm{a}}$} \\
\cline { 2 - 3 } Duration & $\begin{array}{c}\text { Two-day } \\
\text { conference }\end{array}$ & $\begin{array}{c}\text { One-day } \\
\text { workshop }\end{array}$ \\
\hline $\begin{array}{l}\text { 'I believe the PD sessions were long enough for me to } \\
\text { engage with the ideas' }\end{array}$ & 3.10 & 2.98 \\
'I think there would be a benefit from spreading the PD & 1.93 & 2.31 \\
$\quad \begin{array}{l}\text { over more days/sessions' } \\
\text { 'I think a refresher course is needed to remind me of the } \\
\quad \text { details of the PD' }\end{array}$ & 2.69 & 1.81 \\
'I would have preferred more time' & 2.82 & 2.19 \\
'I will need to do more training in this area in the future' & 1.96 & 1.94 \\
'I would like this PD to include follow-up sessions over \\
time'
\end{tabular}

${ }^{a}$ 'Strongly Disagree' =0; 'Disagree' = 1; 'Neutral' = 2; 'Agree' = 3; 'Strongly Agree' $=4$. 
A good opportunity to plan in detail without the usual day to day interference. (Deputy principal, Region 2)

Worthwhile resources, very informative, so great to be able to share with colleagues. (Deputy principal, Region 6)

Although two days away from school is challenging, the benefit if focused uninterrupted and self-directed learning/sessions was great thank you. (Deputy principal, Region 5)

Loved the opportunity to network with other DPs and schools in general. (Deputy principal, Region 5)

Participation as a team of key leaders with time for discussion and reflection was positive and useful. (Deputy principal, Region 5)

Despite appreciating the time to spend with their colleagues, some participants felt there was not enough time to work through the resources provided. However, it was also recognised that extending the duration of the $\mathrm{PD}$ would have been problematic. Thus, finding the correct balance for the duration of the PD needs to be weighed up between the time required for the presentation of materials and opportunities to engage, and limiting the time school leaders are absent from school is a key consideration for such large-scale PD projects:

We were provided with excellent, comprehensive resources but it was difficult to get into them all and progress with work at the same time but any additional time would have been problematic in being out of school. (Head of Junior Secondary, Region 6)

One of the main issues raised in the feedback about duration was that the participants reported that the conference should have been facilitated by the system leadership some time ago, for example:

Brilliant resources and mode of delivery - we needed this program/package 18 months ago - but so grateful for this package now would have loved this 2 days every semester leading up to 2015. (Principal, Region 7)

I believe this PD was poorly timed - just before NAPLAN [National Assessment Program: Literacy and Numeracy (Australian Curriculum, Assessment and Reporting Authority 2013)] and should have been held when we were beginning the JS agenda not when we are at the tail end. (Head of Junior Secondary, Region 3)

With the introduction of Junior Secondary to begin in early 2015, many respondents felt that 'this PD was too late'. They commented on the value and excellence of the resources provided and as such believed that having these earlier would have helped them prepare better for the introduction of Junior Secondary in their schools. In terms of the delivery of the Program, it is not unusual for systems to offer just-in-time PD because this is when it will be best received, and with a reform of such far-reaching effect and with regions having variable PD prior to the implementation of this Program, and with the goal of state-wide consistency, it is likely that schools would need to tailor their learning journey, which is how the Program was designed. The timing of the delivery of this PD Program was outside the control of the project team. One key recommendation from this project was that where large-scale reform is to be undertaken, the PD that supports the reform needs to be provided earlier in the process to ensure consistency and sufficient support for its implementation. 


\section{Content Focus}

Table 5 presents the means for the two-day conference and one-day workshop for each of the nine items assessing Content Focus. Overall, participants agreed most (overall mean was 3.20 and 3.15 respectively) with the statement 'I can see areas related to today's topic where I can improve or learn more', and for the two-day

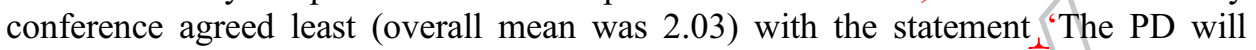
help my school meet the needs of more students' and for the one-day workshop (overall mean was 2.42) with the statement 'This PD did meet my learning goals'. Interestingly, although the school leaders did feel that the PD met their learning goals, they did not feel that the PD would help their school meet the needs of more students. Participants repeatedly noted that the PD was 'late', which may have been due to the stage of the reform journey that these school leaders had already progressed to. However, further questioning would be necessary to be able to accurately reflect the intention behind this response due to the complex nature and diverse settings of schools within this project. For example, there were a significant number of $\mathrm{P}-12$ and $\mathrm{P}-10$ schools that already had the target age group in their schools. For them, this PD may not, in and of itself, help them to meet the needs of more students; but for other schools, preparing to include Year 7 students in their school pre20 cinct for the first time, their attitude could be different.

The analysis of the comments revealed the dominant theme of team planning with a minor theme of materials. There was an overwhelming focus on the opportunity for quality time in school teams and the quality of the resources provided to the leadership teams on the USBs by the Program team. The content focus for the young adolescent learner was particularly valued, because some of the participants

Table 5. Overall mean ratings for the two-day conference and one-day workshop for each of the nine items assessing Content Focus.

\begin{tabular}{|c|c|c|}
\hline \multirow[b]{2}{*}{ Content Focus } & \multicolumn{2}{|c|}{ Mean $^{\mathrm{a}}$} \\
\hline & $\begin{array}{l}\text { Two-day } \\
\text { conference }\end{array}$ & $\begin{array}{l}\text { One-day } \\
\text { workshop }\end{array}$ \\
\hline $\begin{array}{l}\text { 'I gained new knowledge or skills that are related to my } \\
\text { profession' }\end{array}$ & 2.78 & 2.93 \\
\hline $\begin{array}{l}\text { 'I would be able to integrate this PD into my day-to-day } \\
\text { practice' }\end{array}$ & 2.92 & 2.50 \\
\hline 'The PD will enhance the teaching strategies of my staff' & 2.80 & 2.89 \\
\hline $\begin{array}{l}\text { 'I can see areas related to today's topic where I can improve } \\
\text { or learn more' }\end{array}$ & 3.07 & 3.19 \\
\hline $\begin{array}{l}\text { 'The PD topic is important because it links directly to state or } \\
\text { national goals' }\end{array}$ & 3.20 & 3.15 \\
\hline $\begin{array}{l}\text { 'The PD will help my school meet the needs of more } \\
\text { students' }\end{array}$ & 2.03 & 2.46 \\
\hline $\begin{array}{l}\text { 'The PD activity takes into account the learning needs of all } \\
\text { the school leaders in attendance' }\end{array}$ & 2.47 & 2.66 \\
\hline 'This PD did meet my learning goals' & 2.76 & 2.42 \\
\hline $\begin{array}{l}\text { 'I believe my knowledge and skills are enhanced through this } \\
\text { PD' }\end{array}$ & 2.86 & 2.94 \\
\hline
\end{tabular}

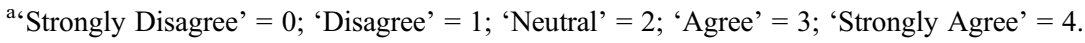


commented that they appreciated this knowledge given this was not an area of expertise for them as secondary trained specialists; for instance:

I need more training in middle school educational/social educational/pedagogical preparedness. (Head of Junior Secondary, Region 6)

I didn't realise how much I had to learn. (Principal, Region 4)

Great suite of resources. (Other, Region 6)

The resources obtained from this PD will be very useful in delivering a consistent message to our school. (Other, Region 2)

Excellent suite of materials ready to use with staff to support, [Aligned with] EQ goals and transform pedagogy. (Deputy principal, Region 1)

One of the main concerns with the content focus was that regions, clusters and schools are unique and distinct. There were, therefore, some comments made highlighting the need for the PD to focus more on where each school was in the journey of Junior Secondary initiation and implementation. While the team had planned the structure and content to be flexible enough for this to occur, there were some participants who still needed guidance and direction in terms of their own contextual focus in order to access the resources relevant to their stage of reform. For some school leaders there was an expectation that resources would be provided without the need for individual leadership teams to contextualise them for their unique school setting. While this was the case for some schools, others felt that the content and pacing was adequate for their particular context and responded positively to the opportunity to shape their reform journey using the tools provided, for example:

Table 6. Overall mean ratings for the two-day conference and one-day workshop for each of the nine items assessing Actiye Learning.

\begin{tabular}{lcc}
\hline & \multicolumn{2}{c}{ Mean $^{\mathrm{a}}$} \\
\cline { 2 - 3 } Active Learning & $\begin{array}{c}\text { Two-day con- } \\
\text { ference }\end{array}$ & $\begin{array}{c}\text { One-day } \\
\text { workshop }\end{array}$ \\
\hline $\begin{array}{l}\text { 'I was given opportunities to practise new skills within the } \\
\text { activity' }\end{array}$ & 2.29 & 2.37 \\
'I was able to observe others modelling/example of good & 2.67 & 3.08 \\
$\quad \begin{array}{l}\text { practice (around the PD topic)' } \\
\text { 'I was able to solve a problem I had or suggest a solution to a } \\
\text { problem someone else had' }\end{array}$ & 2.70 & 2.60 \\
$\begin{array}{l}\text { 'Someone was able to take the lead in the activity other than } \\
\text { the facilitator/s' }\end{array}$ & 2.96 & 2.38 \\
$\begin{array}{l}\text { 'I was able to give feedback on the ideas of others' } \\
\text { 'Leaders were encouraged to share best practice during the } \\
\quad \text { PD' }\end{array}$ & 2.66 & 2.97 \\
$\begin{array}{l}\text { 'I would be able to explain what I have learned to others who } \\
\text { did not attend' }\end{array}$ & 2.98 & 3.12 \\
'I believe that I will be able to apply what I have learned' \\
'I was able to practice skills under simulated conditions and \\
$\quad$ was given feedback'
\end{tabular}

a'Strongly Disagree' = 0; 'Disagree' = 1; 'Neutral' = 2; 'Agree' = 3; 'Strongly Agree' = 4 . 
Mode of delivery allowed for maximum application to our context - frequent and extensive opportunities to plan/discuss with own team whilst simultaneously engaging. (Head of curriculum, Region 7)

\section{Active Learning}

Table 6 presents the overall means for the nine statements assessing Active Learning. Participants responses were very closely aligned between the two surveys and participants agreed most (overall mean was 3.06 [two-day conference] and 3.08 [one-day workshop]) with the statement 'I believe that I will be able to apply what I have learned'. Because of the programme structure of the one-day workshop, participants also rated (overall mean 3.08) the statement 'I was able to observe others modelling/ example of good practice' and agreed least (overall mean was 1.77 and 1.85) with the statement 'I was able to practice skills under simulated conditions and was given feedback'.

An analysis of the comments related to Active Learning revealed that participants most appreciated the ability to 'share ideas', with the minor theme 'more sharing' indicating that participants would have liked the opportunity for more sharing. As already stated, Active Learning related to opportunities to be actively engaging 20 in meaningful discussion, planning and practice during the PD activity and the reality of participants' day-to-day work in their schools. However, there appeared to be some contradictory responses amongst this section of the data. On the one hand, the respondents very much appreciated the sharing and once again the time provided to develop their own school's Action Plan for Junior Secondary implementation. For example, one comment made was Time for action planning and sharing was valuable'. Alternatively, others felt that there was not enough quality examples provided; for example, 'Practical and user friendly examples of signature practice were not displayed'. This could point to the fact that different schools required different needs at the time of the conference presentation in their specific region. Further comments reflecting both opinions are as follows:

More interaction between schools to share knowledge and practices would have been beneficial. (Other, Region 3)

Could have had more sharing from trial schools about their journey - what works what needs to be revisited. (Deputy principal, Region 1)

Loved the delivery mode and the balance of learning from experts, hearing colleagues experiences, team time applying to our context. (Principal, Region 7)

Enjoyed the active participation - this to me is the best PD that a person can get in our profession as you can guide the questions. (Deputy principal, Region 5)

In terms of Active Learning, some participants suggested that the sharing of the schools' development plan and progress was beneficial. This endorsed the plan for the Program team to structure the one-day workshop later in the year as a celebratory and sharing structure for schools and the participants:

The most valuable session for us was session 7 as we were able to share ideas. Further development of this sharing would be more beneficial. (Deputy principal, Region 3 ).

45 During the Program, participants were given significant amounts of time to work through and plan as a leadership team. Although the overall responses for this 
section were comparatively low, this could be due to how the leadership teams interpreted the terms skills, practice and active learning, or where leadership teams were represented by classroom teachers or those with a dual role of school leader and teacher rather than those who were in a purely leadership role. Where participants recognised that for them, as a leadership team, their active learning during the PD was 'planning', their responses were more positive. However, where there was an expectation that the PD would provide them with a list of specific teaching practices or strategies to implement in classrooms, they were not as positive.

\section{Collective Participation}

Table 7 presents the overall mean ratings for the two-day conference and one-day workshop for each of the six items assessing collective participation. Participants agreed most (overall mean was 3.20 and 3.16 respectively) with the statement 'I was able to discuss concepts and skills with colleagues I work closely with'. However, in the two-day conference participants agreed least (overall mean was 2.03) with the statement 'I believe there is a real benefit if several members of a school attend this PD together' but in the one-day workshop agreed least (overall mean was 2.35 ) with the statement 'It is important for all teachers to participate in this activity for me to improve my practice'.

A thematic analysis of the comments related to the core feature of Collective Participation revealed the dominant theme of being given the 'time to plan', with subsequent themes of being given the opportunity for 'collaborative planning' and 'sharing and networking'. This part of the feedback related to the opportunity for contributors to talk about their opinions on the nature of the teamwork in the PD. At times these comments overlapped with the sections listed earlier.

Feedback focused on the positive aspect of being given the chance to have the quality time to spend with their peers to consolidate this planning; for example, 'PD provided the three of us time to share and discuss away from school, The most useful aspect of the seminar was the interaction with peers'. Unique in this part of the

Table 7. Overall mean ratings for the two-day conference and one-day workshop for each of the six items assessing Collective Participation.

\begin{tabular}{lcc}
\hline & \multicolumn{2}{c}{ Mean $^{\mathrm{a}}$} \\
\cline { 2 - 3 } Collective Participation & $\begin{array}{c}\text { Two-day } \\
\text { conference }\end{array}$ & $\begin{array}{c}\text { One-day } \\
\text { workshop }\end{array}$ \\
\hline $\begin{array}{l}\text { 'Peer support will help me apply my learning from this PD } \\
\quad \text { experience' }\end{array}$ & 2.78 & 3.03 \\
'I was able to develop a common understanding of the & 2.92 & 3.05 \\
$\quad$ knowledge or skill with my colleagues' & 2.80 & 2.35 \\
'It is important for all teachers to participate in this activity & & 2.55 \\
$\quad \begin{array}{l}\text { for me to improve my practice' } \\
\text { 'I did planning on my own or with colleagues' }\end{array}$ & 3.07 & 3.16 \\
'I was able to discuss concepts and skills with colleagues I \\
$\quad \begin{array}{l}\text { work closely with' } \\
\text { 'I believe there is a real benefit if several members of a } \\
\text { school attend this PD together' }\end{array}$ & 2.03 & 3.21 \\
\hline
\end{tabular}

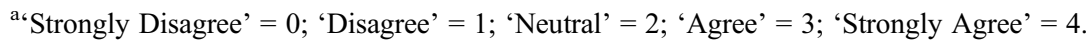


data was that the regions and clusters were very appreciative of the work and support that had already been done;

We already participate in cluster best practice networks - region has facilitated this process very well. (Principal, Region 5)

Our team collectively participates as a high functioning team around planning already.

This would be valuable if we were not doing this already. (Head of Junior Secondary, Region 3)

In this section schools indicated that they were confident to move forward and report on the collective approach that they would take in their planning in relation to such a new initiative. The survey results relating to collective participation highlighted participants' positive perception of the collective approach of the PD (i.e. delivered to school leadership teams) where leadership teams were able to work together. This result confirms Desimone's (2009) findings that collective participation is a powerful form of learning.

\section{Coherence}

20 Table 8 presents the overall means for the two-day conference and one-day workshop for the eight statements assessing Coherence. Participants agreed most (overall mean was 3.15 and 3.18 respectively) with the statement 'Putting what I have learned today into practice can improve student outcomes' and agreed least (overall mean was 0.89 for both sessions) with 'I have not done any training in this area before'. These two pieces of data taken together indicate that participants see coherence between what they learnt at the conference and the ultimate goal of positively impacting on student outcomes and that many schools had already engaged with the reform agenda prior to attendance at the conference.

A thematic analysis of the comments related to coherence revealed the dominant theme of Junior Secondary practices with a minor theme of poor timing. Coherence

Table 8. Overall means for the two-day conference and one-day workshop for the eight statements assessing Coherence.

\begin{tabular}{lcc}
\hline & \multicolumn{2}{c}{ Mean $^{\mathrm{a}}$} \\
\cline { 2 - 3 } Coherence & $\begin{array}{c}\text { Two-day } \\
\text { conference }\end{array}$ & $\begin{array}{c}\text { One-day } \\
\text { workshop }\end{array}$ \\
\hline 'I was able to address any problems that I have experienced & 2.94 & 2.35 \\
$\quad$ in my school' & 3.01 & 3.06 \\
'I will be able to put what I learned today into practice' & 3.15 & 3.18 \\
'Putting what I have learned today into practice can improve & & 2.47 \\
$\quad$ student outcomes' & 3.09 & 2.22 \\
'I can see this topic linking to other professional & & 3.02 \\
$\quad$ development activities' & 2.50 & 0.89 \\
'I already know enough about this topic' & & 0.89 \\
$\quad$ 'Learning about this topic will improve my work & 3.06 & 3.10 \\
'I have not done any training in this area before' & & \\
'I believe there is a direct link between this PD and my day- & & \\
$\quad$ to-day practice as a leader' & & \\
\hline
\end{tabular}

a'Strongly Disagree' = 0; 'Disagree' = 1; 'Neutral' = 2; 'Agree' = 3; 'Strongly Agree' = 4 . 


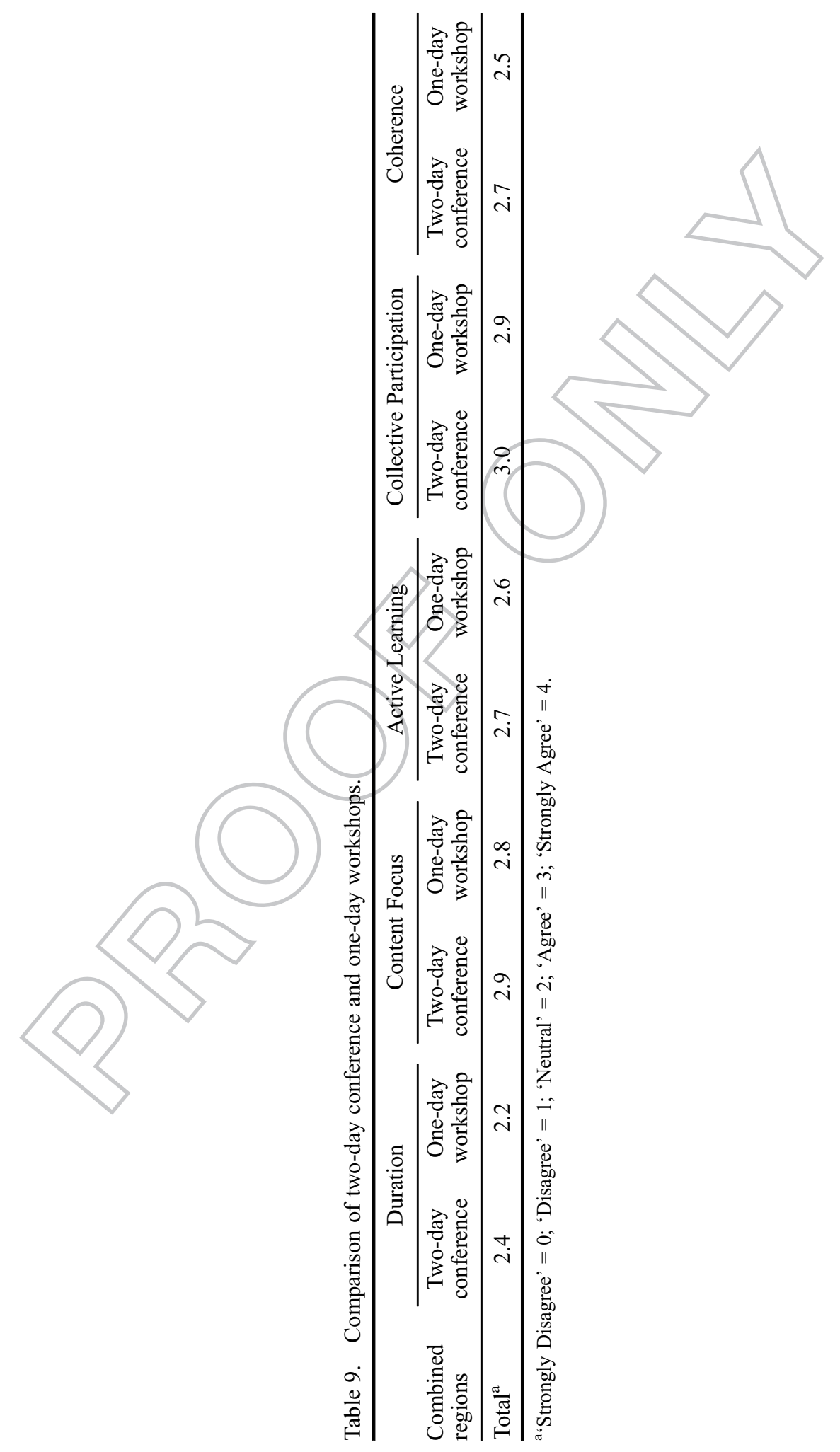


referred to the connection between the PD activity and the reality of the leaders' day-to-day work experiences within their schools. Some of the comments in this section of the feedback were representative of the wide range of readiness, with some schools well advanced in their readiness for the implementation while others were just beginning the journey;

The material provide will be of great use as we continue to implement Junior Secondary. (Deputy principal, Region 7)

I learnt that I had gaps in my knowledge and can now take action to rectify this using the info from the PD. (Principal, Region 3)

10 We have already been through two peer reviews and an external IS readiness review. We have an Action Plan that has been in place since 2012. The information presented is too late. (Principal, Region 3)

Overall, the sentiment from the qualitative comments revealed the Program was worthwhile and relevant. As the teams worked through the resources provided they were able to pick and choose what was most relevant to their situation and focus in on these issues. While it is always difficult to take time out of a school, as a leader (and particularly a whole leadership team), this opportunity is also valuable and this was reflected in the comments generally. Some qualitative comments stated that the Program was provided too late in the process, but there was an equal number of comments that contradicted this view.

\section{Comparing the two-day and one-day events for the five core areas}

By way of summary, Table 9 presents a total for each of the five core areas for the two-day conference compared with the one-day workshop. In each case the one-day workshop scored slightly below the two-day conference and the highest scoring aspect was Collective Participation for both events and the lowest scoring aspect was Duration for both events.

\section{Summary and conclusion}

Implementation of any systemic change is a complex process, especially when the aim is to achieve a consistent approach and implementation has been variably 30 addressed prior to any formal Program being implemented. What is evident from this experience is the need for support in professional learning and resources to ensure that the reform is possible. In this instance, the Queensland government recognised moving Year 7 into High School and the creation of a new tier of schooling - Junior Secondary - as a 'spark' and an opportunity to make sweeping changes

35 and create more developmentally appropriate educational experiences for young adolescents. Its implementation required both a structural and a philosophical response in order to ensure a high level of readiness across the state for all schools. As such, the large investment in infrastructure and human resources was also supported through the building of human capital using targeted PD. With 258 school leadership teams each working in different contexts and on different stages of their reform journey, an innovative and evidence-based PD programme was developed to meet the unique and varied needs of the participants and to facilitate consistency across the state. 
The Program was planned, delivered ${ }_{\Lambda}$ and assessed around Desimone's (2009) five core features for effective PD in this unique setting. Data collected across all stages of the Program indicate that the resources developed and provided to all schools, the expert support and feedback, given through the coaching process and webinars, and the one-day workshops were of great value to most school leadership teams, and the resources and lessons learned would continue to support schools' initiatives in this area. What was also evident from the participants was that the Program may have been more effective had it been delivered earlier in the reform process. This is an important message for those in system leadership roles.

What became evident when planning and delivering the Program was that when a PD programme is designed with these key features in mind, its flexibility is such that all participants were provided with the chance to reflect on their journey to that point, to be introduced to or re-visit underpinning theories around Junior Secondary and have the chance to begin, continue or refine the development of their school's individual Action Plans providing a differentiated and tailored experience for all participants. This was further enhanced through the extensive resource bank provided that assisted each school leadership team in the planning process, particularly in terms of applying theory to practice. School leadership teams appreciated the clear direction provided in terms of working through the materials provided with the aim of developing their school's Action Plans and then being able to receive ongoing feedback through the coaching phase of the Program.

Recommendations arising from the planning and delivery of the Program include that future PD be designed and evaluated in line with the framework that considers the evidence-based features of effective PD: duration, content focus, active learning, collective participation and coherence (Author/s 2015). Furthermore, longitudinal research is essential. An evidence-based programme of review should run alongside the new reform effort to provide empirical data around the effectiveness of initiatives as well as providing audit points for reflection and refinement for individual schools', regions and whole-of-state decisions. A rigorous research agenda should be mapped out to capture the necessary data from the beginning of the state-wide reform implementation in 2015. This research agenda should include a range of data from all Queensland schools to monitor the implementation process as well as ongoing tracking of student outcomes. Opportunities for comparative data with international initiatives should also be considered. The duration of this research should be informed by the timelines of the Educational Change Model: Initiation (one to two years); Development (three to five years); and Consolidation (five to seven years). A major review of the effectiveness of the reform should occur in the four-to-five-year window, in this case 2018-2019.

\section{Disclosure statement}

No potential conflict of interest was reported by the authors.

\section{ORCiD}

Donna Pendergast (D) http://orcid.org/0000-0002-8305-6127 


\section{References}

Australian Council for Educational Research (ACER), 2012. Junior secondary - theory and practice. Brisbane, QLD: Queensland Government, Department of Education and Training.

Australian Curriculum, Assessment and Reporting Authority (ACARA), 2013. National assessment program: literacy and numeracy. Available from: http://www.nap.edu.au/na plan/naplan.html

10 Australian Institute of Teaching and School Leadership (AITSL), 2012. The Australian charter for the professional learning of teachers and school leaders. Carlton South, VIC: Author.

Author/s, 2005. Researching the middle years. In: D. Author/s and N. Bahr, eds. Teaching middle years: rethinking curriculum, pedagogy, and assessment. Crows Nest, NSW: Allen \& Unwin, 88-99).

Author/s, 2006. Fast-tracking middle schooling reform: a model for sustainability. Australian journal of middle schooling, 6 (2), 13-18.

Author/s, 2013. Australian middle years' reform: a focus on teachers and leaders as the subjects and agents of change. In: I.R. Haslam, M.S. Khine and I.M. Saleh, eds. Large scale reform and social capital building: the professional development imperative. London, UK: Routledge, 180-197.

Author/s, 2015. Core features of effective continuing professional development for the middle years - a tool for reflection. Research in middle level online, 38 (10), 1-18.

Author/s, et al., 2005. Developing lifelong learners in the middle years of schooling. Brisbane, QLD: The University of Queensland.

Author/s, et al., 2014. An ongoing journey: evaluation of the Junior Secondary Leading Change Development Program. Brisbane, QLD: DET.

Department of Education and Training (DET), 2010. A flying start for Queensland children: education green paper. Brisbane, QLD: Author.

30 Desimone, L.M., 2009. Improving impact studies of teachers' professional development: toward better conceptualizations and measures. Educational researcher, 38 (3), 181-199.

Fullan, M., 2001. Leading in a culture of change. San Francisco: Jossey-Bass.

Garvis, S., et al., 2013. The Victorian early years learning and development framework: managing change in a complex environment. Australasian journal of early childhood, 38

\section{$35 \quad(2), 86-94$.}

Guskey, T.R., 2002. Does it make a difference? Evaluating professional development. Educational leadership, 59 (6), 45-51.

Guskey, T.R. 2009. Closing the knowledge gap on effective professional development. Educational horizons, 87 (4), 224-233.

40 Hallinger, P. and Heck, R.H., 2010. Collaborative leadership and school improvement: understanding the impact on school capacity and student learning. School leadership and management, 30 (2), 95-110.

Hargreaves, A., 2002. Sustainability of educational change: the role of social geographies. Journal of educational change, 3 (3-4), 189-214.

45 Hargreaves, A. and Fink, D., 2012. Sustainable leadership (Vol. 6). New York, NY: John Wiley \& Sons.

Hill, H.C., Beisiegel, M., and Jacob, R., 2013. Professional development research: consensus, crossroads, and challenges. Educational researcher, 42 (9), 476-497.

Kotter, J., 1996. Leading change. Boston, MA: Harvard Business School Press.

50 Kotter, J. and Cohen, D., 2002. The heart of change. Boston, MA: Harvard Business School Press.

Luke, A., et al., 2003. Beyond the middle: a report about literacy and numeracy development of target group students in the middle years of schooling, Vol. 1. Brisbane, QLD: McMillan.

55 McGee, C., et al., 2003. Transition to secondary school: a literature review. New Zealand: Ministry of Education.

Middle Years of Schooling Association, 2008. MYSA position paper. Middle schooling: people, practices and places. Brisbane, QLD: Author. 
Ministerial Council on Education, Employment, Training and Youth Affairs (MYCEETYA), 2008. Melbourne declaration on educational goals for young Australians. Available from: http://www.curriculum.edu.au/verve/_resources/National_Declaration_on_the_Edu cational_Goals_for_Young_Australians.pdf

Mourshed, M., Chijioke, C., and Barber, M., 2010. How the world's most improved school systems keep getting better. Available from: http://mckinseyonsociety.com/how-theworlds-most-improved-school-systems-keep-getting-better/

Mouza, C., 2009. Does research-based professional development make a difference? A longitudinal investigation of teacher learning in technology integration. Teachers college record, 111 (5), 1195-1241.

National Middle School Association (NMSA), 2001. This we believe - and now we must act. Westerville, OH: National Middle School Association.

O’Brien, R., 2006. Good, better, best. Teacher, 1 (9), 7-8.

Organisation for Economic Cooperation and Development (OECD), 2015. Education policy outlook 2015: making reforms happen. doi:10.1787/9789264225442-en.

Queensland Government, 2015. Year 7 is moving to high school. Available from: https:// www.qld.gov.au/education/schools/programs/pages/year7.html

Riley, K., 2000. Leadership, learning and systemic reform. Journal of educational change, 1, $29-55$.

Schleicher, A., 2012. Preparing teachers and developing school leaders for the 21st century: lessons from around the world. France: OECD Publishing. 2, rue Andre Pascal, F-75775 Paris Cedex 16.

Smith, A.E., 2006. Evaluation of unsupervised semantic mapping of natural language with Leximancer concept mapping. Behaviour research methods, 38 (2), 262-279.

Stevens, R.J., 2004. Why do educational innovations come and go? What do we know? What can we do? Teaching and teacher education, 20 (4), 389-396.

Vagle, V., 2012. Not a stage! A critical re-conception of young adolescent education. New York, NY: Peter Lang Publishing. 